3. Before the advent of the MCA 2005, the common law defence of necessity allowed a surgeon to save the life of (or prevent irremediable harm to) an incompetent patient, usually in a clinical emergency. It needs to be understood that this doctrine would be entirely inapplicable to the case of the elderly patient that Dr Bogod is considering. The 'legal vacuum' that he describes would quite clearly have been filled, prior to the MCA 2005, by a carefully considered clinical decision on the basis of her best interest. If this had proved contentious, it would have been dealt with under the inherent jurisdiction of the High Court.

This procedure has simply been codified into statute by the MCA 2005. Translated into the language of this new law, temporarily incapacitated patients can be operated on solely on the basis of their best interests only to save life or prevent irremediable harm. So if you wish to repair a ruptured aortic aneurysm in an incompetent patient, the 'defence of necessity' is all you require. However, if you wish to replace a hip as an elective procedure, the defence has no role whatsoever since the intervention is not immediately necessary and there should be ample opportunity first to determine the patient's best interests and then act accordingly.

4. The reason why surgeons are so frequently reminded not to regard consent as valid 'no matter how much time has passed' is mainly because unbeknownst to the surgeon, the patient's circumstances (as opposed to the risks and benefits of the procedure) may have changed. The patient may have: a new job, or lost their old one; new family; new mortgage; new partner; lost a child; been widowed; made bankrupt... and all of these may have altered the patient's attitude to whether the surgery is still appropriate from their perspective.

5. In determining what information to provide, you should be guided, as Dr Bogod asserts, by what the reasonable patient would want to know - the reasonable patient being an honourable descendant of the man on the Clapham omnibus. The difficulty with being guided by what a 'particular patient needs to know' (as the Summary suggests) is that you have absolutely no idea what that might be. Naturally, we have a duty to answer any questions during the disclosure process, thus allowing us to get as close as possible to the particular patient's requirements, but how can we possibly know what the person in front of us regards as the cornerstone of his or her decision? It is for this reason that in most jurisdictions, courts have established something approaching an objective standard (in English law: the reasonable patient) for whose benefit doctors formulate the disclosure of risks, benefits, alternatives, etc.

\section{Simplified minimally invasive invasive parathyroidectomy}

SP Balasubramanian, BJ Harrison

Sheffield Teaching Hospitals NHS Foundation Trust, Sheffield, UK doi $10.1308 / 147870811 \times 598542$

\section{CORRESPONDENCE TO}

Saba Balasubramanian, E: s.p.balasubramanian@sheffield.ac.uk

\section{COMMENT ON}

Wong W, Foo FJ, Lau MI, Sarin A, Kiruparan P. Simplified minimally invasive invasive parathyroidectomy: a series of 100 cases and a review of the literature. Ann $R$ Coll Surg Eng/ 2011; 93: 290-293 doi $10.1308 / 003588411 \times 571836$

We agree with Wong et al that minimally invasive parathyroidectomy (MIP) is a safe and effective option in selected patients (approximately 50\% of those with primary hyperparathyroidism) but would like to comment on some aspects of methodology and conclusions as reported in their case series.

The authors quote a reference from $2003^{1}$ to support their assertion that only a small minority of consultant members of the British Association of Endocrine and Thyroid Surgeons (BAETS) were using the lateral incision approach. The third national audit of the BAETS database in 2009 showed that a targeted approach was used in $35 \%$ of patients who underwent first time surgery for primary hyperparathyroidism. ${ }^{2}$

The series by Wong et al reports only on patients in whom MIP was attempted. We assume that there would be other patients with primary hyperparathyroidism who underwent planned bilateral exploration. From an epidemiological perspective (and for readers to obtain a greater insight and perspective into the authors' practice), it is important that the article includes details of all patients who underwent surgery and the results of imaging in those patients who underwent bilateral exploration. In addition, restricting reporting of accuracy of technetium sestamibi (MIBI) scans and ultrasonography to only those who underwent MIP would grossly exaggerate the tests' reported success.

In the Methods section, Wong et al state that ultrasonography and/or MIBI scans were used for localisation. A systematic literature review and evidence-based guideline ${ }^{\tilde{z}}$ confirms our view that unilateral/targeted parathyroidectomy should be used only if MIBI and ultrasonography results are concordant. If parathyroid localisation studies are non-concordant, or only a single scan is positive, the appropriate approach should be bilateral neck exploration or targeted parathyroidectomy with intraoperative parathyroid hormone (IOPTH) assay.

The use of $7.5 \mathrm{mg} / \mathrm{kg}$ of body weight of intravenous methylene blue is an unnecessarily high dose that has the potential to cause serious neurotoxicity. ${ }^{4}$ The most appropriate 'maximum permitted dose' for intravenous methylene blue has been debated in the literature before. ${ }^{5}$ The general consensus and recommendation by the UK National 
Poisons Information Service is that the dose of methylene blue should not exceed $4 \mathrm{mg} / \mathrm{kg}$ of body weight. ${ }^{6,7}$

The algorithm presented by Wong et al needs further clarification. It seems to suggest that a decision to use IOPTH is made during surgery when a 'suspicious lesion' has been found. To use IOPTH in an appropriate and effective manner, a basal sample for PTH should be drawn before incision. Use of this modality during the operation (without a basal sample) may give erroneous and misleading results. Perhaps the authors can further explain their technique and whether this has been validated?

Finally, Wong et al's argument that 'MIP has been shown to be the superior approach' is based on differences in outcomes shown in an observational study where MIP has only been used in 'selected' cases. ${ }^{8}$

\section{References}

1. Ozbas S, Pain S, Tang T, Wishart GC. Surgical management of primary hyperparathyroidism - results of a national survey. Ann R Coll Surg Engl 2003; 85: 236-241

2. British Association of Endocrine and Thyroid Surgeons. Third National Audit Report. London: BAETS; 2009.

3. Mihai R, Simon D, Hellman P. Imaging for primary hyperparathyroidism - an evidence-based analysis. Langenbecks Arch Surg 2009; 394: 765-784.

4. Khan MA, North AP, Chadwick DR. Prolonged postoperative altered mental status after methylene blue infusion during parathyroidectomy: a case report and review of the literature. Ann R Coll Surg Eng/ 2007; 89: W9-W11.

5. Ahmed TS. Methylene blue toxicity following infusion to localize parathyroid adenoma. J Laryngol Otol 2006; 120: 708.

6. Majithia A, Stearns MP. Methylene blue toxicity following infusion to localize parathyroid adenoma. J Laryngol Otol 2006; 120: 138-140.

7. Martindale SJ, Stedeford JC. Neurological sequelae following methylene blue injection for parathyroidectomy. Anaesthesia 2003; 58: 1,041-1,042.

8. Udelsman R. Six hundred fifty-six consecutive explorations for primary hyperparathyroidism. Ann Surg 2002; 235: 665-670.

\section{Hip resurfacing revision rates: radiological audit of risk factors}

IS Grewal, HA Kazi, MR Cope

Southport and Ormskirk NHS Hospital Trust, UK

doi 10.1308/147870811X598579

CORRESPONDENCE TO

Ishvinder Grewal, E: ishi@doctors.org.uk

\section{COMMENT ON}

Ramisetty N, Krishnan KM, Partington PF. Hip resurfacing revision rates: radiological audit of risk factors. Ann R Coll Surg Eng/ 2011; 93: 314-316

doi $10.1308 / 003588411 \times 571115$

We read the article by Ramisetty et al with interest. Nevertheless, we have some concerns with the methodology. The study was retrospective and so there was no standardisation of the radiographs.

The authors' method of measuring the neck angle has been demonstrated to be inaccurate ${ }^{1}$ in that as little as $7^{\circ}$ of external rotation of the hip can result in more than $10^{\circ}$ change in the apparent neck shaft angle (NSA) and up to $10^{\circ}$ can be elicited by internal rotation. Wilson et al reported that when using a picture archiving and communication system to measure the NSA of the proximal femur, the reliability of the measurement is only $\pm 6^{\circ}$ for different observers even under the best conditions. ${ }^{2}$ In the study by Ramisetty et al the valgus angle of the hip resurfacings that were revised only varied from $4^{\circ}$ to $-6^{\circ}$. With an error of $6^{\circ}$ in measurement alone, it is impossible to predict failure from this.

Murray described that the cup inclination angle (CIA) was better measured with computed tomography as opposed to a plain anteroposterior (AP) radiograph. ${ }^{3}$ This is in part due to the variation of angles from which AP radiographs are taken. The correct calculation is the angle between the major axis of the ellipse and the transverse body axis. If the cup is anteverted, then the apparent inclination is an overestimate of the radiographic inclination: $\operatorname{Tan}(\mathrm{RI})=$ $\operatorname{Tan}(\mathrm{CI}) / \operatorname{Cos}^{2}(\mathrm{OA})$. The greater the anteversion, the greater the overestimation. ${ }^{4}$

The topic of this paper is of interest but, unfortunately, due to the inherent errors highlighted above, the results do not translate into the ability to clinically predict failure.

\section{References}

1. Kay RM, Jaki KA, Skaggs DL. The effect of femoral rotation on the projected femoral neck-shaft angle. J Pediatr Orthop 2000; 20: 736-739.

2. Wilson JD, Eardley W, Odak S, Jennings A. To what degree is digital imaging reliable? Validation of femoral neck shaft angle measurement in the era of picture archiving and communication systems. Br J Radiol 2011; 84: 375-379.

3. Murray DW. The definition and measurement of acetabular orientation. J Bone Joint Surg Br 1993; 75: 228-232.

4. Ackland MK, Bourne WB, Uhthoff HK. Anteversion of the acetabular cup: measurement of angle after total hip replacement. J Bone Joint Surg Br 1986, 68: 409-413.

\section{Authors' response}

N Ramisetty ${ }^{1}$, KM Krishnan ${ }^{1}$, PF Partington ${ }^{2}$

${ }^{1}$ Northern Deanery, Newcastle upon Tyne, UK

${ }^{2}$ Wansbeck General Hospital, Ashington, UK

doi 10.1308/147870811X598588

\section{CORRESPONDENCE TO}

Narendra Ramisetty, E: narenrami@yahoo.co.uk

We appreciate the interest of Grewal et al in our article. We would like to point out that in our study the revision rate was higher in a valgus than in a varus stem shaft angle, contrary to what one would expect, although this was not statistically significant. This part of our study is therefore not clinically relevant.

The revision rate was higher for patients with a cup inclination angle (CIA) of $>60^{\circ}$. We agree that our method of measuring the CIA may not be highly accurate but this is the standard method in the day-to-day clinic setting. This was also the standard method of assessing the CIA in some other recently published studies. ${ }^{1-3}$ Tannast et al performed computed tomography of 37 total hip arthroplasties and compared them with standard pelvic radiographs. ${ }^{4}$ They concluded that the hip CIA could be measured reliably with standard pelvic radiographs. The aim of our study was not to predict risk factors for failure; this is already evident in the 